\title{
Relation between ABO blood group and Helicobacter pylori infection among patients with peptic ulcer disease at Provincial Hospital: A cross sectional study
}

\author{
Mahesh Mahaseth $^{1 *}$, Gaurang Mishra', Sanjeet Jha1, Manish Pandey ${ }^{1}$, Gyanendra Yadav1, Gautam Sah' \\ ${ }^{1}$ Department of Medicine, Provincial hospital, Province-2, Janakpur, Nepal
}

\section{ARTICLE INFO}

Article history:

Received: 7 January 2021

Revised: 27 April 2021

Accepted: 21 May 2021

*Correspondence:

Dr. Mahesh Mahaseth,

Janakpur Provincial hospital, Janakpur, Nepal.

E-mail:

mahesh522362@gmail.com

Citation:

Mahaseth M, Mishra G, Jha S,

Pandey M, Yadav G, Sah G.

Relation between $\mathrm{ABO}$ blood group and Helicobacter pylori infection among patients with peptic ulcer disease attending a Provincial Hospital in Nepal: A cross sectional study. MedS. J.

Med. Sci.2021;1(1):95-100

\begin{abstract}
ABSTARCT
INDRODUCTION: To document the potential relationship between Helicobacter pylori infection (H. pylori), $\mathrm{ABO}$ and Rhesus (Rh) blood groups in affected individuals with peptic ulcer disorder. MATERIALS AND METHODS: This cross-sectional, research was accomplished from February 2021 to May 2021 among individuals experiencing dyspeptic conditions visiting Endoscopy Unit of Janakpur Provincial Hospital. All the patients were investigated for their blood group phenotype and Rhesus dependent through slide hemagglutination test. Also all the patients went through esophagogastroduodenoscopy (EGD) in order to identify peptic ulcer disease. Gastric biopsies were acquired and evaluated for $\mathrm{H}$. pylori through urease test. RESULTS: A total of 103 patients were registered in this study, which included 49 males and 54 females with a mean age of $15-77$ years. $H$. pylori was found positive in $75(72.8 \%)$ cases and negative in $28(27.2 \%)$ cases, Blood group $\mathrm{A}, \mathrm{B}, \mathrm{AB}$ and $\mathrm{O}$ were found in $19.4 \%$, $33.0 \%, 13.6 \%$, and $34.0 \%$ of the patients respectively. Relatively higher prevalence of $\mathrm{H}$. pylori was found in each blood groups $\mathrm{O}(33.3 \%)$ and $\mathrm{B}(33.3 \%)$ compared to blood group $\mathrm{A}(20.1 \%)$ and $\mathrm{AB}(13.3 \%)$. However, association of $\mathrm{ABO}$ blood group and prevalence of $\mathrm{H}$. pylori was found to be insignificant $(\mathrm{p}=0.991)$. CONCLUSIONS: The study concluded that B blood group people were more prone to $\mathrm{H}$. pylori infection. Our study revealed that $H$. pylori contamination was definitely an endemic issue, which needs to be handled by enhancing hygiene, supply of filtered water and in addition other measures for its elimination. Further meticulous studies are needed to establish relationship between blood type and $\mathrm{H}$. pylori contamination in different age groups.
\end{abstract}

Keywords: ABO blood groups, H. pylori, peptic ulcer disease

\section{INTRODUCTION}

Helicobacter pylori is a Gram negative spiralshaped microorganism which resides in the stomach mucosa of human beings. It exist in somewhere around $50 \%$ of the globe's human population [1,2]. It is actually associated with various range of clinical stomach problems, which includes peptic ulcer disorder, stomach cancers and stomach MALT lymphoma [2]. The main reservoir is definitely the human being stomach and its transmission most likely takes place by individual passageway. Frequency/rate of H. pylori infection is typically a lot higher in developing nations, compared to the western world. However, there are subgroups within numerous locations with increased $\mathrm{H}$. pylori occurrence compared with the overall human population. The occurrence of $\mathrm{H}$. pylori differs by geographical location, cultural background, socioeconomic circumstances and different age groups [2]. The components through which $\mathrm{H}$. pylori is generally contaminated and its particular path of transmission continue to be uncertain. Prior epidemiological scientific studies demonstrated that domestic personal hygiene tactics and socioeconomic condition as determined by profession, household earnings and dwelling circumstances were very important risks for $\mathrm{H}$. 
pylori contamination $[3,4]$. These elements are believed to clarify, why the rate of $\mathrm{H}$. pylori disease differs among communities. One particular genetically established attribute with acknowledged polymorphic expression concerning persons and communities, includes captivated curiosity as probable hazard aspects for $\mathrm{H}$. pylori contamination is ABO blood group [5,6].

Considering that duodenal ulcer disorder is related to antral $\mathrm{H}$. pylori infection in $90-100 \%$ of scenarios, blood group $\mathrm{O}$ could likewise be a threat issue aimed for contracting $\mathrm{H}$. pylori infection. $\mathrm{ABO}$ blood group seem to be looked into as risks for $\mathrm{H}$. pylori related stomach malignancy, nevertheless, there are actually inconsistent scientific studies because of numerous confounding outcomes [7]. Due to breakthrough discovery with the $\mathrm{ABO}$ blood group, there is a continuing curiosity about the possible character of blood groups cutting-edge transmittable disorders. Blood group antigens have the receptor properties for toxins, parasitic organisms and bacteria, exactly where this bacteria could assist in annexation or intrusion and avert multitude approval components [8].

Therefore, this study was aimed to observe the relationship involving $\mathrm{ABO}$ blood group and $\mathrm{H}$. pylori contamination status of Nepalese community in a Provincial hospital.

\section{MATERIALS AND METHODS}

Study design and setting

This study was a cross-sectional government hospital-based research carried out from February 2021 to May 2021 at Provincial hospital, Janakpur, Nepal. The study design was approved by Provincial hospital board, Janakpur. All included patients, suffering from dyspeptic indicators had undergone endoscopic procedure at Janakpur Provincial hospital-Endoscopy unit, in order to find out the conceivable association between $\mathrm{H}$. pylori infection, $\mathrm{ABO}$ and Rhesus (Rh) blood groups in Nepalese patients with peptic ulcer disease (PUD).

Patients and study procedures

A total number of 103 patients who had been identified as having PUD by esophagogastroduodenoscopy (EGD) in Janakpur
Provincial hospital-Endoscopy unit were included in this study after their written consent. In case of children's, consent was obtained from their parents.

Patients consuming anti-secretory drugs or proton pump inhibitors two weeks prior to EGD and the ones currently having an active stomach internal bleeding were omitted in the research. Gastric antral biopsies were assessed for the presence of $\mathrm{H}$. Pylori by urease test. A colour alteration between red or pink in 5 to 30 minutes was regarded as favourable. Blood group phenotypes were dependent on the slide hemagglutination technique, and were linked with H. pylori infection in those patients. The characteristic of affected individual and scientific details was accumulated simply by using a verbal survey.

\section{Statistical considerations}

Data were entered in MS Excel and then transferred to SPSS version 23.0 for statistical analysis. Frequency and percentage were reported for categorical data. Mean and standard deviation were calculated for continuous data. Furthermore, Chisquare test was applied to observe the association of H. Pylori with blood group and other demographic variables. A p-value $<0.05$ was considered as statistically significant.

\section{RESULTS}

Among the 103 patients with peptic ulcer disease included in the study, H. pylori was found positive in $75(72.8 \%)$ cases and negative in $28(27.2 \%)$ cases (Figure 1).

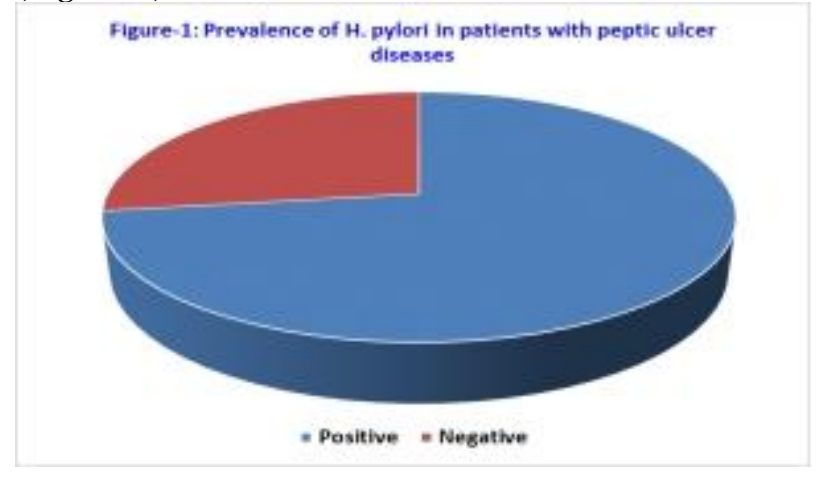

The median age of patients was 37 years, and majority $(73.8 \%)$ of the patients were under 30 years of age. $47.6 \%$ of the patients were male whereas 
more than half of the patients were females (52.4\%). Blood group $\mathrm{A}, \mathrm{B}, \mathrm{AB}$ and $\mathrm{O}$ were found in $19.4 \%$, $33.0 \%$, $13.6 \%$, and $34.0 \%$ of the patients respectively. None of the patients was found $\mathrm{Rh}$ negating during the study period (Table 1 ).

Relatively higher prevalence of $\mathrm{H}$. pylori was found in blood groups, $\mathrm{O}(33.3 \%)$ and $\mathrm{B}(33.3 \%)$ compared to blood groups, A (20.1\%) and AB (13.3\%).
However, association of $\mathrm{ABO}$ blood group and prevalence of $\mathrm{H}$. pylori was found to be insignificant $(\mathrm{p}=0.991)$. H. pylori was found more among patient's aged 30 years and above $(80.0 \%)$ and in males (50.7\%). Age group was found to have significant $(p=0.019)$ but gender was found to have insignificant $(p=0.303)$ relationship with the prevalence of $\mathrm{H}$. pylori among patients with peptic ulcer disease (Table 2).

\begin{tabular}{llll}
\hline \multicolumn{2}{l}{ Table-1| Demographic characteristics of patients with peptic ulcer disease } & \\
\hline Characteristics & Category & Frequency & Percentage (\%) \\
\hline Age & Median (Range): years & $37(15-77)$ & - \\
Age group & Less than 30 years & 27 & 26.2 \\
& 30 years and above & 76 & 73.8 \\
Sex & Male & 49 & 47.6 \\
& Female & 54 & 52.4 \\
Blood Group & A & 20 & 19.4 \\
& B & 34 & 33.0 \\
& AB & 14 & 13.6 \\
Rh factor & O & 35 & 34.0 \\
& Positive & 103 & 100 \\
\hline
\end{tabular}

Table 2 I ABO blood group and demographic characteristics associated with H. Pylori among patients with peptic ulcer disease

\begin{tabular}{|c|c|c|c|}
\hline \multirow[b]{2}{*}{ Characteristics } & \multicolumn{2}{|c|}{ H. Pylori } & \multirow{2}{*}{$\begin{array}{l}-p-\text { value for } \\
\text { Chi-square test }\end{array}$} \\
\hline & $\begin{array}{l}\text { Negative } \\
\mathrm{n}=\mathbf{2 8}(\%)\end{array}$ & $\begin{array}{l}\text { Positive } \\
\mathrm{n}=75(\%)\end{array}$ & \\
\hline \multicolumn{4}{|c|}{ Blood Group (Rh) } \\
\hline A (Positive) & $5(17.9)$ & $15(20.1)$ & 0.991 \\
\hline B (Positive) & $9(32.1)$ & $25(33.3)$ & \\
\hline AB (Positive) & $4(14.3)$ & $10(13.3)$ & \\
\hline O (Positive) & $10(35.7)$ & $25(33.3)$ & \\
\hline \multicolumn{4}{|c|}{ Age group (years) } \\
\hline Less than 30 & $12(42.9)$ & $15(20.0)$ & 0.019 \\
\hline 30 and more & $16(57.1)$ & $60(80.0)$ & \\
\hline \multicolumn{4}{|l|}{ Sex } \\
\hline Male & 11(39.3) & $38(50.7)$ & 0.303 \\
\hline Female & $17(60.7)$ & $37(49.3)$ & \\
\hline
\end{tabular}

\section{DISCUSSION}

One of the several obstacles of $\mathrm{H}$. pylori scientific studies have determined why more and more people carry it, somewhere around 50\%. Whereas, only roughly $20 \%$ of the people turn out to be unwell. Studies have demonstrated that H. pylori virulence variables, the cytotoxin-associated gene product A (cagA) and vacuolating cytotoxin A (vacA), in combination with host and environment aspects, could be actually significant $[9,10]$. The category I H. pylori contamination proportion was substantially increased in individuals with predominant veggie eating habits compared to those who had increased proteins in their diet. 
Studies show the appreciable links of $\mathrm{H}$. pylori seropositivity, which has a minimal rate of recurrence of consuming various meats [11].

The portion of men and women with antibodies to $\mathrm{H}$. pylori was greater within the young age ranges in contrast to those documented for comparable age groups in western Europe [12]. In our study, most of the patient belonged to young age group and the association of $\mathrm{H}$. Pylori infection could be due to improper personal hygiene and water issue. One genetically established attribute with acknowledged polymorphic appearance in between men and women and communities included captivated curiosity as danger aspects for $\mathrm{H}$. pylori infection is $\mathrm{ABO}$ blood group [5]. We found that there was definite danger to get $H$. pylori infection in communities, which included captivated curiosity as danger aspects.

Considering the breakthrough with $\mathrm{ABO}$ blood group, we have seen a continuing curiosity about the possible function of blood groups in contagious disorder. Blood group antigens are receptors for toxic compounds, harmful bacteria, wherever they are able to accomplish colonization or avoid host clearance mechanisms [8]. Preceding research established that blood-group antigen-binding adhesion (BabA) mediates sticking with of $\mathrm{H}$. pylori to human Lewis's blood-group antigens on gastric epithelial cells $[13,14]$.

Throughout the previous years, proof to the part of $\mathrm{ABO}$ groups as danger components for $\mathrm{H}$. pylori contamination has appeared from innate model scientific research and epidemiologic data $[15,16]$. We believe that there is an association of $\mathrm{H}$. pylori contamination in community, and it is noteworthy to have a detailed evaluation of community to figure out the epidemiologic data. Recent research with more than 12,000 individuals who looked into the association involving $\mathrm{ABO}$ blood group besides $\mathrm{H}$. pylori infection, demonstrated that $\mathrm{O}$ blood group was connected with an approximated 16.3\% surge in odds of $\mathrm{H}$. pylori infection than the non-O blood group, that has been extremely statistically substantial [17]. In our study blood group $B$ and $O$ had higher likelihood of $\mathrm{H}$. Pylori infection. However, our sample size is modest, and it is needed to evaluate in large-volume sample.
Blood group B and AB had approximately $17 \%$ and $29 \%$ decreased in the likelihood of $H$. pylori infection, in comparison with non- $B$, non- $A B$ likewise. The outcomes failed to differ significantly with the over-all relationship when noticing research space between the developing and the western world [17].

The primary mechanism to the connection involving $\mathrm{ABO}$ blood group and $\mathrm{H}$. pylori infection continues to be suggested from prior biological research in $\mathrm{ABO}$, Lewis and Secretor histological blood system [14, 18]. People from O blood group resounding the secretor phenotype transformed the forerunner's oligosaccharide type 1 into $\mathrm{H}$ antigen type 1 but because of the deficiency of GTA as well as GTB glycosyltransferases, it did not appear to produce $\mathrm{O}$ and $\mathrm{B}$ antigens. Consequently, it transformed $\mathrm{H}$ type one antigen into Leb antigen in Lewis's constructive persons in around $90 \%$ of individuals [14]. The prime measurable appearance of the antigen within the gastrointestinal mucosa of O blood group people having the secretor phenotype generally seem to boost the inclination towards an infection by $\mathrm{H}$. pylori [14].

Studies didn't document information on detailed straining of $\mathrm{H}$. pylori with regards to $\mathrm{ABO}$ group. Experimental research has demonstrated strain reliant on predilection of BabA adhesin(s) in binding to MUC5AC glycoforms replaced with Leb which might make contributions in the inter individual variation in host-microbe relationships [19].

Our results ought to be taken in light of the subsequent limits. The lack of approach to contact and upshot valuations besides deviation within the communities analyzed. This study is worthy, and it may be useful in the future review for community based H.pylori assessment and for providing proper treatment accordingly. However, study has some limitations. Firstly, our sample size was quite less and secondly, there was no direct genetic evaluation due to lack of resources. Random selection of case depending on the chief complaint of epigastric pain was only assessed and included in this study. 


\section{CONCLUSIONS:}

Comprehending the transforming developments in $\mathrm{H}$. pylori epidemiology, specific transmitting pathways, and also the microbial and host factors ultimately causing gastroduodenal disease continue to be difficulties in this region. Worldwide epidemiological research, improvements in technology, and medical treatments have incorporated to assist shed light on the mechanisms of conversation in between this common microorganism and its particular host, which lead to various clinical expressions.

Our research, is innovative and most preliminary within province- 2 of Nepal. It is usually figured that $\mathrm{H}$. pylori contamination is definitely an endemic issue, which needs to be handled by enhancing hygiene and filtered supply of water and in addition ought to be looked into for elimination. It could possibly be determined that B blood group people are more prone to $\mathrm{H}$. pylori infection and its particular pointing to gastrointestinal issues. However, the sample size is the modest, further study is needed to validate more cellular and immunological response to it than other $\mathrm{ABO}$ blood group's, even though no substantial distinctions between $\mathrm{Rh}+$ and $\mathrm{Rh}$ - patients were observed. Furthermore, it could be determined that women and young people are most likely going to contract H. pylori infection. Nevertheless, good eminent scientific research is needed to determine the interconnection, which can considerably assist within comprehending the exact pathology and rule out $H$. pylori infection and find out possible precautionary approaches.

\section{ADDITIONAL INFORMATION AND DECLARATIONS}

Funding: Self

Competing Interests: The authors declare no competing interests.

Author Contributions: Concept and design: M.M, GM. and M.P; Statistical analysis: M.M, G.S, SJ and; writing of the manuscript M.M, GM. and M.P ,S.J,M. M,G.S:; revision and editing of the manuscript: M.M, GM. and M.P; All authors have contributed to literature review, analysis, interpretation of result, and revision, and all have read and agreed with the content of the manuscript

Data Availability: Data will be available upon request to corresponding authors after valid reason.

\section{REFERENCES}

1. Mégraud F, Brassens-Rabbé $\mathrm{MP}$, Denis F, Belbouri A, Hoa DQ: Seroepidemiology of Campylobacter pylori infection in various populations. Journal of clinical microbiology. 1989;27(8):1870-73.

2. Go MF: Review article: natural history and epidemiology of Helicobacter pylori infection. Alimentary pharmacology \& therapeutics. 2002;16 Suppl 1:315 .

3. Graham DY, Malaty HM, Evans DG, Evans DJ, Jr., Klein PD, Adam E: Epidemiology of Helicobacter pylori in an asymptomatic population in the
United States. Effect of age, race, and socioeconomic status. Gastroenterology. 1991;100(6):1495-1501.

4. Malaty HM, Evans DG, Evans DJ, Jr., Graham DY: Helicobacter pylori in Hispanics: comparison with blacks and whites of similar age and socioeconomic class. Gastroenterology. 1992;103(3):813-16.

5. Rossez Y, Maes E, Lefebvre Darroman T, Gosset P, Ecobichon C, Joncquel Chevalier Curt M, Boneca IG, Michalski JC, Robbe-Masselot C: Almost all human gastric mucin O-glycans harbor blood group A, B or $\mathrm{H}$ antigens and are potential binding sites for Helicobacter pylori. Glycobiology. 2012;22(9):1193-1206.

6. Malaty HM, Engstrand L, Pedersen NL, Graham DY: Helicobacter pylori infection: genetic and environmental influences. A study of twins. Annals of internal medicine. 1994;120(12):982-86.

7. Oh S, Kim N, Kwon JW, Shin CM, Choi YJ, Lee DH, Jung HC: Effect of Helicobacter pylori Eradication and ABO Genotype on Gastric Cancer Development. Helicobacter. 2016;21(6):596-605. 
8. Cooling L: Blood Groups in Infection and Host Susceptibility. Clinical microbiology reviews. 2015; 28(3):801-70.

9. Liu YE, Gong $Y H$, Sun LP, Xu Q, Yuan Y: The relationship between $H$. pylori virulence genotypes and gastric diseases. Polish journal of microbiology. 2012;61(2):147-50.

10. Shimoyama $T$, Crabtree JE: Bacterial factors and immune pathogenesis in Helicobacter pylori infection. Gut. 1998;43 Suppl 1(Suppl 1):S2-5.

11. Alvarado-Esquivel C: Seroepidemiology of Helicobacter pylori infection in a Mennonite community in Durango State, Mexico. Helicobacter. 2013;18(3):215-21.

12. Pateraki E, Mentis A, Spiliadis C, Sophianos D, Stergiatou I, Skandalis N, Weir DM: Seroepidemiology of Helicobacter pylori infection in Greece. FEMS microbiology immunology. 1990;2(3):129-36.
13. Borén $T$, Normark $S$, Falk P: Helicobacter pylori: molecular basis for host recognition and bacterial adherence. Trends in microbiology. 1994;2(7):221-28.

14. Borén $T$, Falk $P$, Roth KA, Larson G, Normark S: Attachment of Helicobacter pylori to human gastric epithelium mediated by blood group antigens. Science (New York, NY). 1993;262(5141):1892-95.

15. Kanbay M, Gür G, Arslan H, Yilmaz U, Boyacioglu S: The relationship of $\mathrm{ABO}$ blood group, age, gender, smoking, and Helicobacter pylori infection. Digestive diseases and sciences. 2005;50(7):1214-17.

16. Loffeld RJ, Stobberingh E: Helicobacter pylori and $\mathrm{ABO}$ blood groups. Journal of clinical pathology. 1991;44(6):516-17.

17. Chakrani $Z$, Robinson $K$, Taye B: Association Between ABO Blood Groups and Helicobacter pylori Infection: A Meta-Analysis. 2018;8(1):17604.
18. Aspholm-Hurtig M, Dailide G, Lahmann M, Kalia A, Ilver D, Roche N, Vikström S, Sjöström R, Lindén $S$, Bäckström $\backslash \mathrm{A}$ et al: Functional adaptation of BabA, the $\mathrm{H}$. pylori $\mathrm{ABO}$ blood group antigen binding adhesin. Science (New York, NY). 2004;305(5683):519-22.

19. Lindén $S$, Nordman $H$, Hedenbro J, Hurtig M, Borén T, Carlstedt I: Strain- and blood group-dependent binding of Helicobacter pylori to human gastric MUC5AC glycoforms. Gastroenterology. 2002; 123(6):1923-30. 